A MEDIAÇÃO COMUNITÁRIA COMO PRESSUPOSTO DE REALIZAÇÃO DO CONCEITO DE SEGURANCCA CIDADÃ: ANÁLISE DO PROGRAMA JUSTIÇA COMUNITÁRIA DESENVOLVIDO PELO TRIBUNAL DE JUSTICCA DO DISTRITO FEDERAL

\title{
A MEDIAÇÃO COMUNITÁRIA COMO PRESSUPOSTO DE REALIZAÇÃO DO CONCEITO DE SEGURANÇA CIDADÃ: ANÁLISE DO PROGRAMA JUSTIÇA COMUNITÁRIA DESENVOLVIDO PELO TRIBUNAL DE JUSTIÇA DO DISTRITO FEDERAL
}

\section{COMMUNITY MEDIATION AS A PRECONDITION TO IMPLEMENT THE CONCEPT OF CITIZEN SAFETY: AN ANALYSIS OF THE COMMUNITY JUSTICE PROGRAM DEVELOPED BY THE COURT OF JUSTICE OF DISTRITO FEDERAL}

\author{
SiLvana Colombo \\ Doutoranda em Direito PUC/PR. \\ Mestre em Direito Universidade de Caxias do Sul (UCS). Advogada. \\ sil_colombo@ibest.com.br \\ VLADIMIR PASSOS DE FREITAS
}

Mestre e Doutor pela Universidade Federal do Paraná (UFPR). Professor de direito ambiental do Programa de Pós-graduação em Direito da Pontifícia Universidade Católica (PUC $P R)$. Desembargador federal aposentado do TRF 4 região.

vladimir.freitas@terra.com.br

\section{RESUMO}

0 presente artigo analisa a Segurança Pública a partir da Constituição Federal de 1988 e do paradigma da Segurança Cidadã. Após uma breve abordagem do conceito e dos paradigmas relacionados ao tema, aborda-se os métodos alternativos de solução de conflitos na área de Segurança Pública, em especial, a mediação comunitária. Ao final, faz um relato do programa desenvolvido pelo Tribunal de Justiça do Distrito Federal, denominado Justiça comunitária. Para tanto, utiliza-se o método dedutivo e a revisão bibliográfica.

Palavras-chave: mediação; participação; prevenção; segurança cidadã.

\begin{abstract}
This paper analyzes Public Security from the Brazilian Federal Constitution of 1988 and the paradigm of Citizen Safety. After a brief approach of the concept and the paradigms related to the topic, this study discusses alternative methods of conflict resolution in the area of Public Security, in particular, community mediation. In the end, it gives an account of the program developed by the Court of Justice of Distrito Federal, called Community Justice. To achieve this purpose, it uses the deductive method and literature review.
\end{abstract}

Keywords: mediation; participation; prevention; citizen safety. 
A MEDIAÇÃO COMUNITÁRIA COMO PRESSUPOSTO DE REALIZAÇÃO DO CONCEITO DE SEGURANÇA CIDADÃ: ANÁLISE DO PROGRAMA JUSTIÇA COMUNITÁRIA DESENVOLVIDO PELO TRIBUNAL DE JUSTIÇA DO DISTRITO FEDERAL

\section{SUMÁRIO}

INTRODUÇÃO; 1 SEGURANÇA PÚBLICA NA CONSTITUIÇÃO FEDERAL DE 1988; 1.1 Segurança Cidadã; 2 MÉTODOS ALTERNATIVOS DE SOLUÇÃO DE CONFLITOS (MASCS); 2.1 Mediação comunitária; 3 MEDIAÇÃO COMUNITÁRIA A PARTIR DO PROGRAMA DE JUSTIÇA COMUNITÁRIA DESENVOLVIDO PELO TRIBUNAL DE JUSTIÇA DO DISTRITO FEDERAL; CONCLUSÃO; REFERÊNCIAS.

\section{INTRODUÇÃO}

A temática da Segurança Pública ganha importância a partir da consagração na Constituição Federal como direito fundamental - direito e dever dos cidadãos e também do Estado. Neste sentido, a sua constitucionalização trouxe como consequência a necessidade da legislação infraconstitucional estar adequada ao texto da Constituição, assim como a definição e execução de políticas públicas e a atuação dos órgãos responsáveis pela segurança, que precisam estar em consonância com os direitos fundamentais.

Apesar disso, a construção do paradigma da Segurança Cidadã é essencial para o direito porque traz a necessidade de participação da população, a atuação dos órgãos de segurança pública de forma preventiva, a aproximação da polícia com a comunidade na qual irá atuar, e a implementação de políticas setoriais.

Tendo como base o pressuposto da Segurança Cidadã, o presente artigo volta à atenção para métodos alternativos de solução de conflitos na área de Segurança Pública, entre eles, destaca-se a mediação comunitária. Pretende-se, portanto, trazer à tona o debate acerca da necessidade da atuação preventiva do Estado e dos órgãos de segurança pública como forma de combater a violência, e não apenas repressivamente.

0 que se pretende investigar no decorrer do artigo é se o paradigma da Segurança Cidadã está ou não incorporada nas práticas realizadas pelos órgãos responsáveis pela segurança pública. Para tanto, num primeiro momento aborda-se o tema da Segurança Púbica na Constituição de 1988, além da conceituação e pressupostos da Segurança Cidadã. Após a diferenciação dos métodos alternativos de solução de conflitos, a ênfase será na mediação comunitária. Por fim, será apresentado o Programa da Justiça Comunitária desenvolvido pelo Tribunal de Justiça do Distrito Federal, um exemplo de mediação comunitária. 
A MEDIAÇÃO COMUNITÁRIA COMO PRESSUPOSTO DE REALIZAÇÃO DO CONCEITO DE SEGURANÇA CIDADÃ: ANÁLISE DO PROGRAMA JUSTIÇA COMUNITÁRIA DESENVOLVIDO PELO TRIBUNAL DE JUSTIÇA DO DISTRITO FEDERAL

\section{SEGURANÇA PÚBLICA NA CONSTITUIÇÃO FEDERAL DE 1988}

Antes de ser abordado de forma especifica o tema Segurança Pública na atual Constituição Federal, importa mencionar que a formulação de políticas públicas e a atuação do Estado nesta área sofrem influência do paradigma ${ }^{1}$ conceitual adotado na área da Segurança Pública.

Nas últimas cinco décadas, três paradigmas na área de Segurança Pública ganham destaque, a saber: Segurança Nacional, Segurança Pública e Segurança Cidadã. ${ }^{2} 0$ primeiro paradigma se desenvolve no período de ditadura militar, caracterizado pela supressão de direitos constitucionais e também pela ruptura do princípio da soberania popular, previsto no artigo $1^{\circ}$, parágrafo único, da Constituição. Esta fase foi marcada pela doutrina da Segurança Nacional, que priorizava a defesa do Estado e a supremacia do interesse nacional. Dito de outra forma, aquilo que atentava contra o Estado e contra os interesses nacionais ameaçava à Segurança e justificava a atuação do Estado repressivamente, mesmo que isto representasse a violação de direitos. ${ }^{3}$

Encerrado o período da Ditadura Militar, inicia-se uma nova fase, marcada pelo paradigma da Segurança Pública, presente na Constituição democrática de 1988, que inova ao estabelecer que a Segurança Pública é direito do cidadão e também dever deste e do Estado em garanti-la, entretanto, permanece com uma política voltada para o controle e repressão da violência.

Afirma-se, então, que a atual Constituição brasileira disciplinou de forma detalhada a temática segurança pública nos seus artigos $5^{\circ}$ e 144 , ao estabelecer que esta é dever do Estado e direito fundamental do cidadão, que também é responsável pela sua efetivação. Estabelece, ainda, a finalidade da segurança pública, qual seja, a preservação da ordem pública e da incolumidade das pessoas e do patrimônio.

Expressa, ainda, a Constituição, em seu artigo 142, o papel das Forças Armadas no contexto da Segurança Pública, responsável agora pela manutenção da soberania nacional,

\footnotetext{
1 "Os paradigmas são as realizações cientificas universalmente reconhecidas que, durante algum tempo, fornece problemas e soluções modelares para uma comunidade de praticantes de uma ciência". KUHN, Thomas. S. A estrutura das revoluções científicas. São Paulo: Perspectiva, 1991, p.13.

2 PAMPLONA, Danielle. 0 conceito de segurança -cidadã como um novo paradigma para políticas públicas de segurança. [artigo não publicado, fornecido pela autora do texto]

${ }^{3}$ FREIRE, Moema Dutra. Paradigmas de Segurança no Brasil: da Ditadura aos nossos dias. Revista Aurora, ano III, n. 5, dez, 2009.
} 
A MEDIAÇÃO COMUNITÁRIA COMO PRESSUPOSTO DE REALIZAÇÃO DO CONCEITO DE SEGURANÇA CIDADÃ: ANÁLISE DO PROGRAMA JUSTIÇA COMUNITÁRIA DESENVOLVIDO PELO TRIBUNAL DE JUSTIÇA DO DISTRITO FEDERAL

SiLVANA COLOMBO VLADIMIR PASSOS DE FREITAS

defesa da pátria e garantia dos poderes constitucionais. Disto é possível extrair que o texto constitucional se omitiu na definição da atuação dos municípios e de outras instituições governamentais na área de Segurança Pública, ao atribuir de forma prioritária a responsabilidade para os Estados. ${ }^{4}$

O Supremo Tribunal Federal já se manifestou acerca do caráter de fundamentalidade do direito à segurança pública, conforme pode ser extraído da jurisprudência abaixo relacionada:

O direito à segurança é prerrogativa constitucional indisponível, garantido mediante a implementação de políticas públicas, impondo ao Estado a obrigação de criar condições objetivas que possibilitem o efetivo acesso a tal serviço. É possível ao Poder Judiciário determinar a implementação pelo Estado, quando inadimplente, de políticas públicas constitucionalmente previstas, sem que haja ingerência em questão que envolve o poder discricionário do Poder Executivo ${ }^{5}$.

Quanto aos órgãos responsáveis pela segurança pública, o texto constitucional prevê que são compostos por órgãos normativos (Secretaria Nacional de Segurança Pública e Secretarias Estaduais de Segurança Pública), órgãos policiais (Polícia Federal, Polícia Rodoviária Federal, Polícia Militar, Polícia civil) e os Conselhos Regionais que tem a "competência de realizar o planejamento integrado e a coordenação de ações de segurança pública de interesse comum, tendo em vista que estas extrapolam os limites das unidades federadas".

A primeira consequência da constitucionalização da segurança pública é a necessidade de as leis sobre a matéria, a nível federal, estadual e municipal, estarem de acordo com o texto constitucional. Em segundo lugar, legitima o Estado na formulação e execução das políticas de segurança. Por fim, determina que a atuação dos órgãos e autoridades policiais deve ser pautada pelo respeito aos direitos fundamentais e aos princípios constitucionais como a cidadania, democracia e dignidade da pessoa humana. ${ }^{6}$

Esta concepção democrática de segurança pública exige uma polícia que se aproxima da comunidade e seja transparente e não discriminatória, com a finalidade de garantir o exercício

\footnotetext{
${ }^{4}$ FREIRE, Moema Dutra. Paradigmas de Segurança no Brasil: da Ditadura aos nossos dias. Revista Aurora, ano III, n. 5, dez, 2009.

${ }^{5}$ BRASIL. Supremo Tribunal Federal. Acórdão de decisão que negou provimento ao agravo regimental em recurso extraordinário sobre ingerência no poder discricionário do Poder Executivo em relação a políticas públicas. Recurso Extraordinário n 559.646. Ministério Público do Estado do Paraná e Estado do Paraná. Relator: Ministra Ellen Gracie. 07 de junho de 2011. Disponível em: <http:/ / redir.stf.jus.br/paginadorpub/paginador.jsp?docTP=AC\&docID=624471 >. Acesso em:

6 SOUZA NETO, Cláudio Pereira. A segurança pública na Constituição federal de 1988: conceituação adequada, competências federativas e órgãos de execução das política. Revista de Direito do Estado, v. 8, p. 19-73, 2007.
} 
A MEDIAÇÃO COMUNITÁRIA COMO PRESSUPOSTO DE REALIZAÇÃO DO CONCEITO DE SEGURANÇA CIDADÃ: ANÁLISE DO PROGRAMA JUSTIÇA COMUNITÁRIA DESENVOLVIDO PELO TRIBUNAL DE JUSTIÇA DO DISTRITO FEDERAL

SiLVANA COLOMBO VLADIMIR PASSOS DE FREITAS

da cidadania, por meio da prevenção e/ou repressão da criminalidade e da violência. Neste sentido, emerge na América Latina, na década de 90, o terceiro paradigma denominado de Segurança Cidadã, que "tem como princípio a implementação integrada de políticas setoriais no nível local”7, tema que será objeto de análise no próximo item.

\subsection{Segurança Cidadã}

O crescimento da criminalidade no Brasil e a confiança pouco expressiva da população nas instituições de segurança pública e na justiça criminal ${ }^{8}$ impulsionaram um novo olhar sobre o tema Segurança Pública que, a partir da década de 90, começa a ser pensado sob o prisma da prevenção, do respeito aos direitos fundamentais e da participação conjunta da sociedade civil e Estado na tarefa de combate à criminalidade. ${ }^{9}$

Diante desta realidade, a segurança pública pautada até então pelo paradigma repressivo deve ser substituído por um paradigma de prevenção e de política integral de proteção de direitos. Isto significa dizer que a esfera penal, especialmente o sistema prisional, deve ser reservada para situações graves, como por exemplo, a violência contra a pessoa. ${ }^{10}$

Surge, então, a terminologia Segurança Cidadã, adotada por organismos internacionais, e que apresenta como alicerce o envolvimento da comunidade com questões relacionadas à segurança, às práticas preventivas e aperfeiçoamento da gestão de segurança. O Programa das Nações Unidas (PNDU) entende que a segurança é um termo amplo que envolve segurança econômica, alimentar, ambiental, pessoal, comunitária e política, além de estar pautada pelo respeito à vida e a dignidade. ${ }^{11}$ Extrai-se da definição de Segurança Cidadã prevista no relatório de desenvolvimento humano:

\footnotetext{
${ }^{7}$ FREIRE, Moema Dutra. Paradigmas de Segurança no Brasil: da Ditadura aos nossos dias. Aurora, ano III, $\mathrm{n}$. 5, dez, 2009, p.52.

${ }^{8} \mathrm{O}$ percentual da população que não confia nas polícias brasileiras cresceu $14 \%$ entre os primeiros semestres de 2012 e 2013. 70,1\% da população ouvida pela pesquisa declara não confiar nas polícias, percentual próximo do observado para partidos políticos, que são os mais mal avaliados pela pesquisa $(95,1 \%)$.

9 LIANA, de Paula; GODINHO, Letícia. Os governos subnacionais na gestão de segurança cidadã: experiência brasileira. Disponível em: <www.bibliotecadigital.fgv.br>.

${ }^{10}$ ANDRADE, Vera Regina Pereira de. A Mudança do Paradigma Repressivo em Segurança Pública: reflexões criminológicas críticas em torno da proposta da $1^{\circ}$ Conferência Nacional Brasileira de Segurança Pública. Sequência, n. 67, p. 335-356, dez, 2013.

11 SERRATO, Héctor Riveros. Projeto Regional de Governabilidade local para a América Latina-PNDU. Disponível em: <www.pndu.org.br/marcoconceitualpndu_segurancacidada>. Acesso em: 15 maio 2015.
} 
A MEDIAÇÃO COMUNITÁRIA COMO PRESSUPOSTO DE REALIZAÇÃO DO CONCEITO DE SEGURANÇA CIDADÃ: ANÁLISE DO PROGRAMA JUSTIÇA COMUNITÁRIA DESENVOLVIDO PELO TRIBUNAL DE JUSTIÇA DO DISTRITO FEDERAL

Ao se falar em segurança cidadã ou segurança pública, faz-se alusão a uma dimensão mais ampla do que a mera sobrevivência física. A segurança é uma criação cultural que, hoje em dia, implica uma forma igualitária (não hierárquica) de sociabilidade, um âmbito compartilhado livremente por todos. Essa forma de trato civilizado representa o fundamento para que cada pessoa possa desdobrar sua subjetividade em interação com os demais. Está em jogo não somente a vida da pessoa individual, mas também a da sociedade. ${ }^{12}$

A Segurança Cidadã é uma forma de intervenção sobre a segurança pública pautada pela atuação multissetorial, ou seja, com a efetiva participação de atores estatais e não estatais. Isto é, a responsabilidade pela segurança pública não pode ficar adstrita aos órgãos policiais, o que implica na participação de outros atores sociais neste processo, como por exemplo, as municipalidades e a defesa civil, o que está de acordo com a previsão constitucional.

Dito de outra forma, o conceito de Segurança Cidadã envolve três aspectos importantes: primeiro, a participação dos órgãos governamentais e da sociedade civil; segundo, a definição e implementação de ações necessárias para redução dos índices de violência, incluindo a atuação em áreas como educação, saúde, cultura, esporte, lazer e cidadania; e terceiro, o foco na prevenção à violência.

Neste paradigma, uma política pública de Segurança Cidadã envolve cinco formas de intervenção, definida pelo Programa das Nações Unidas:

(i) As dirigidas ao cumprimento voluntário de normas;

(ii) As que buscam a inclusão social e a diminuição de fatores de risco (álcool, drogas e armas);

(iii) As que têm como propósito a melhoria dos contextos urbanos associados ao medo e ao perigo real (recuperação de espaços públicos)

(iv) As que facilitam o acesso dos cidadãos a mecanismos institucionais e/ou alternativos de resolução de conflitos; e

(v) As que possuem foco na construção de capacidades institucionais, melhoria da eficácia policial e das autoridades executivas ou judiciais e da confiança dos cidadãos em tais instituições. ${ }^{13}$

Destaca-se que a Constituição Federal de 1988 representa um marco da evolução paradigmática em segurança no país, especialmente porque amplia a participação dos cidadãos na formulação de políticas públicas, que passam a ser beneficiários e agentes neste processo.

\footnotetext{
12 PNDU. Rumo a uma política integral de convivência de segurança cidadã na América Latina: março conceitual de interpretação-ação. Programa das Nações Unidas para o desenvolvimento, Mimeo, 2005. ${ }^{13}$ Ibid.
} 
A MEDIAÇÃO COMUNITÁRIA COMO PRESSUPOSTO DE REALIZAÇÃO DO CONCEITO DE SEGURANÇA CIDADÃ: ANÁLISE DO PROGRAMA JUSTIÇA COMUNITÁRIA DESENVOLVIDO PELO TRIBUNAL DE JUSTIÇA DO DISTRITO FEDERAL

SiLVANA COLOMBO VLADIMIR PASSOS DE FREITAS

Além disso, a partir da descentralização federativa, reforça o papel dos Estados e dos Municípios na tarefa de prevenção à violência.

0 que se pretende é a aproximação da atuação das políticas públicas com o conceito de Segurança Cidadã. Em relação a este aspecto, no Brasil, a inserção deste paradigma se faz presente de forma incipiente em alguns programas desenvolvidos nos Estados da Federação. Além disso, há parceria de cooperação técnica estabelecida entre a Secretaria de Segurança Pública e as Nações Unidas e também o Programa Nacional de Segurança Pública com cidadania ${ }^{14}$ (PRONASCI). ${ }^{15}$

Apesar da tendência de inserção do conceito de Segurança Cidadã na gestão das políticas de combate e, especialmente, de prevenção da violência, sua transposição prática se depara com a resistência na articulação de políticas setoriais (educação, saúde, cidadania) pelos órgãos responsáveis pela segurança. ${ }^{16}$

Feitas estas breves considerações, serão abordados os Métodos Alternativos de Solução de Conflitos (MASCs), já que uma das premissas do paradigma de Segurança Cidadã é a facilitação dos cidadãos ao acesso à Justiça, à prevenção, e a disponibilização de formas efetivas de resolução de conflitos na área da segurança.

\section{MÉTOdOS ALTERNATIVOS DE SOLUÇÃO DE CONFLITOS (MASCS)}

A administração de conflitos na área da segurança esteve pautada até então pela atuação repressiva do Estado e dos órgãos responsáveis. Entretanto, a partir do processo de democratização e participação popular, sedimentado pela Constituição de 1988, e também da propagação da ideia de Segurança Cidadã, ganham importância os métodos alternativos de resolução de conflitos, entre eles, a negociação, conciliação, mediação e arbitragem, por se constituírem em opções mais céleres e efetivas do que o sistema judicial.

\footnotetext{
14 “O Programa Nacional de Segurança Pública com Cidadania (Pronasci) foi um marco nas políticas públicas de segurança do Brasil, uma vez que promoveu inúmeras inovações. Foi um grande impulsionador da compreensão de que a segurança pública é uma questão transversal, que demanda intervenção de várias áreas do poder público, de maneira integrada, não apenas com repressão, mas também com prevenção". Disponível em:www.portal.mj.gov.br/pronasci.Acesso em:28 de abril de 2015.

15 FREIRE, Moema Dutra. Paradigmas de Segurança no Brasil: da Ditadura aos nossos dias. Revista Aurora, ano III, n. 5, dez, 2009.

${ }^{16}$ Ibid.
} 
A MEDIAÇÃO COMUNITÁRIA COMO PRESSUPOSTO DE REALIZAÇÃO DO CONCEITO DE SEGURANÇA CIDADÃ: ANÁLISE DO PROGRAMA JUSTIÇA COMUNITÁRIA DESENVOLVIDO PELO TRIBUNAL DE JUSTIÇA DO DISTRITO FEDERAL

Silvana Colombo VLADIMIR PASSOS DE FREITAS

Salienta-se que a Organização das Nações Unidas estabeleceu na Resolução n.26 de 28 de julho de 1999, que os Estados devem promover a utilização dos mecanismos alternativos de solução de conflitos, paralelamente ao sistema judicial. Isto significa que a promoção destes mecanismos deve ser uma "política pública de justiça não judiciária". ${ }^{17}$ Além disso, a Resolução 125, de 29.11.2010 do Conselho Nacional de Justiça que versa sobre a "Política Judiciária Nacional de Tratamento Adequado dos Conflitos", estabelece no Artigo $1^{\circ}$ que deve ser assegurado a todos o direito à solução dos conflitos por meios adequados a sua natureza e peculiaridade.

A mencionada resolução foi estabelecida sob a premissa do direito ao acesso à justiça, prevista no artigo $5^{\circ}, \mathrm{XXXV}$, da Constituição Federal, no reconhecimento da conciliação e a mediação como instrumentos efetivos de pacificação social, solução e prevenção de litígios, e também do Judiciário estabelecer política pública de tratamento adequado dos problemas jurídicos e dos conflitos de interesse. ${ }^{18}$ Dito isto, é necessário conceituar cada um destes meios de resolução de conflitos para que seja possível diferenciá-los e, posteriormente, trazer alguns exemplos de aplicação na área de Segurança Pública nos estados da federação, em especial, no Estado do Paraná e Santa Catarina.

Inicia-se pela negociação, que pode ser conceituada como uma técnica de resolução de conflitos por meio da qual as partes em litígio buscam a solução deste, em regra, sem a intermediação de terceiros. Apesar da sua informalidade, pode ser considerada como técnica de resolução de conflitos, porque estabelece um processo de comunicação entre as partes envolvidas com a finalidade de construção de um consenso acerca da disputa estabelecida. ${ }^{19}$

A conciliação $0^{20}$ é uma forma de resolução pacífica de conflitos em que as partes confiam a uma terceira pessoa, chamada de conciliador, que objetiva aproximá-las e ajudá-las na construção de um acordo. Para Maurício Godinho Delgado:

A conciliação, por sua vez, é o método de solução de conflitos em que as partes agem na composição, mas dirigidas por um terceiro, destituído do poder decisório final, que se mantém com os próprios sujeitos originais da relação jurídica conflituosa. Contudo, a força condutora da dinâmica conciliatória por

\footnotetext{
${ }^{17}$ SECRETARIA DE SEGURANÇA PÚBLICA DE SÃO PAULO. Polícia Comunitária. Disponível em: <www.ssp.sp.gov.br/acoes/acoes_comunitario.aspx>. Acesso em: 07 abr. 2015, p.7.

${ }^{18}$ CONSELHO NACIONAL DE JUSTIÇA. Resolução $\mathrm{N}^{\circ} 125$ de 29 de novembro de 2010. Disponível em: <http://www.cnj.jus.br/atos-normativos?documento=156>. Acesso em: 12 maio 2015.

${ }^{19}$ TARTUCCE, Fernanda. Mediação nos conflitos civis. Rio de Janeiro: Forense, 2008.

${ }^{20}$ A conciliação também pode ser judicial, neste caso, o próprio juiz do processo atua como conciliador.
} 
A MEDIAÇÃO COMUNITÁRIA COMO PRESSUPOSTO DE REALIZAÇÃO DO CONCEITO DE SEGURANÇA CIDADÃ: ANÁLISE DO PROGRAMA JUSTIÇA COMUNITÁRIA DESENVOLVIDO PELO TRIBUNAL DE JUSTIÇA DO DISTRITO FEDERAL

SILVANA COLOMBO VLADIMIR PASSOS DE FREITAS

esse terceiro é real, muitas vezes conseguindo implementar resultado não imaginado ou querido, primitivamente, pelas partes (...). ${ }^{21}$

Quanto à mediação, esta pode ser caracterizada como uma técnica de resolução de conflitos por meio do qual uma terceira pessoa auxilia as partes a chegarem a uma solução consensual. Nas palavras de Juan Carlos Veluzza:

Mediação é a técnica privada de solução de conflitos que vem demonstrando, no mundo, sua grande eficiência nos conflitos interpessoais, pois com ela são as próprias partes que acham as soluções. 0 mediador somente as ajuda a procurálas, introduzindo, com suas técnicas, os critérios e os raciocínios que thes permitirão um entendimento melhor ${ }^{22}$

Nesta técnica, o mediador não tem o poder de decidir o conflito de forma imperativa, ou seja, ele atua como facilitador da comunicação/diálogo entre as partes, que tem a responsabilidade de chegar a um consenso. Dito de outra forma, a "mediação (judicial ou extrajudicial) propicia aos contendores o encontro da solução amigável capaz de resolver definitivamente a controvérsia, seja pela conciliação ou pela transação". ${ }^{23}$

Já a arbitragem é uma via jurisdicional de solução pacífica dos conflitos, na qual as partes têm a liberdade de escolher o árbitro, delimitar o direito aplicável e estabelecer com que critérios ele deve dirimir a matéria conflituosa. Em outras palavras, os sujeitos das relações jurídicas têm a possibilidade de atribuir ao árbitro o poder de decidir a controvérsia, conforme as regras convencionadas por elas. É o entendimento de Carlos Alberto Carmona:

A arbitragem, de forma ampla, é uma técnica para solução de controvérsias através da intervenção de uma ou mais pessoas que recebem seus poderes de uma convenção privada, decidindo com base nesta convenção, sem intervenção do Estado, sendo a decisão destinada a assumir a eficácia de sentença judicial. ${ }^{24}$

No que tange às características da arbitragem, o fato dela ser um "mecanismo jurisdicional, porém não judiciário, de solução pacífica de conflitos”, o árbitro é escolhido ad

${ }^{21}$ DELGADO, Maurício Goudinho. Curso de direito do trabalho. São Paulo: Ltr, 2010, p.1346.

${ }^{22}$ VEZZULLA, Juan Carlos. Teoria e Prática da Mediação. Paraná: Instituto de Mediação e Arbitragem do Brasil, 1998, p.56.

${ }^{23}$ FIGUEIRA JÚNIOR, Joel Dias. Arbitragem. Legislação Nacional e Estrangeira e o Monopólio Jurisdicional. São Paulo: LTR, 1999.

${ }^{24}$ CARMONA, Carlos Alberto. A Arbitragem no Processo Civil Brasileiro. São Paulo: Malheiros, 1993, p.19. 
A MEDIAÇÃO COMUNITÁRIA COMO PRESSUPOSTO DE REALIZAÇÃO DO CONCEITO DE SEGURANÇA CIDADÃ: ANÁLISE DO PROGRAMA JUSTIÇA COMUNITÁRIA DESENVOLVIDO PELO TRIBUNAL DE JUSTIÇA DO DISTRITO FEDERAL

SiLVANA COLOMBO VLADIMIR PASSOS DE FREITAS

hoc pelas partes, portanto, ele não tem permanência, sua função jurisdicional é transitória e está limitada à matéria confiada pelas partes.

Importante mencionar a diferença entre conciliação, mediação e arbitragem, todas consideradas meios alternativos de solução de conflitos. As duas primeiras pressupõem a intervenção de uma terceira pessoa, entretanto, o mediador pode interferir diretamente na solução do conflito. Quanto à arbitragem, é mecanismo de resolução de conflito realizado por um terceiro escolhido pelas partes, sendo que a decisão as vincula e é passível de execução. ${ }^{25}$

Menciona-se, também, que apesar das semelhanças entre conciliação e a mediação, ambas se diferenciam em função do papel exercido pela terceira pessoa na resolução do conflito: "a atividade do mediador é mais intensa que a do conciliador, pois aquele toma mais iniciativas que este, não só realizando propostas de conciliação, mas persuadindo as partes para que cheguem a uma solução do conflito". ${ }^{26}$

Dentre as técnicas de solução alternativa de conflitos, será objeto de estudo a mediação comunitária, que tem sido utilizada para resolver os conflitos na área de segurança pública.

\subsection{Mediação comunitária}

Como estudado anteriormente, a mediação comunitária é uma técnica de resolução de conflitos de caráter informal, na qual o mediador facilita a comunicação entre as partes para que possam chegar a um consenso satisfatório, mas não tem o poder de decidir nem sugerir uma solução para as mesmas. A mediação comunitária pode ser compreendida “como sendo o meio alternativo de resolução de conflitos que possibilita às partes, através da ajuda de um terceiro imparcial (o mediador), manter o diálogo, construindo assim uma solução satisfatória para o problema, preservando o relacionamento entre elas". ${ }^{27}$

Cabe lembrar que a mediação é regida pelos seguintes princípios $^{28}$ : (a) liberdade das partes, isto é, são elas que devem optar de forma voluntária pela mediação; (b) poder de decisão das partes, pois o mediado não tem a função de impor sua decisão; (c) não competitividade, ou seja, o conflito é superado pelo diálogo entre os envolvidos, neste sentido,

\footnotetext{
${ }^{25}$ DOS SANTOS, Ricardo Stersi. Noções gerais da arbitragem. Florianópolis: Fundação Boiteux, 2004.

${ }^{26}$ SCHIAVI, Mauro. Manual de direito processual do trabalho. $3^{\circ}$ ed. São Paulo: Ltr, 2010, p.34.

${ }^{27}$ MARANHÃO, Ministério Público. Manual de mediação comunitária/ Adaptação de Vicente de Paulo Silva Martins. São Luís: Procuradoria Geral de Justiça, 2008. p.23.

28 SPENGLER, Fabiana Marion; SPENGLER NETO, Theobaldo. Mediação enquanto política pública: o conflito, a crise da jurisdição e as práticas mediativas. Santa Cruz do Sul: EDUNISC, 2012.
} 
A MEDIAÇÃO COMUNITÁRIA COMO PRESSUPOSTO DE REALIZAÇÃO DO CONCEITO DE SEGURANÇA CIDADÃ: ANÁLISE DO PROGRAMA JUSTIÇA COMUNITÁRIA DESENVOLVIDO PELO TRIBUNAL DE JUSTIÇA DO DISTRITO FEDERAL

SILVANA COLOMBO VLADIMIR PASSOS DE FREITAS

não existe a figura de perdedor e vencedor; (d) competência do mediador, devendo ser imparcial e conhecer a realidade da comunidade; (e) confidencialidade, o que significa dizer que devem ser evitados constrangimentos da publicidade do conflito mediado e das partes. ${ }^{29}$

Nesta perspectiva, o ponto positivo da mediação comunitária é permitir a participação da população na resolução de seus próprios conflitos, o que possibilita a efetivação da cidadania na medida em que a comunidade torna-se consciente de seus direitos e deveres e atua de forma ativa em prol da comunidade. Acrescenta-se, ainda, que a mediação contribui diretamente para a comunidade porque:

- Reforça a cultura de paz, através do estímulo ao diálogo e da solução pacífica dos casos em disputa;

- Reforça a democracia direta, através da participação cidadã em temas que envolvam interesses coletivos e o monitoramento do poder público;

- Aproxima o discurso do direito à realidade da comunidade, respeitando as diferenças e fazendo destas um potencial de crescimento;

- Estimula o surgimento de novos paradigmas no tratamento de diferenças, produzindo transformações culturais em âmbito coletivo e individual;

- Atua de maneira interdisciplinar e autônoma;

- Desenvolve uma ação preventiva de conflitos;

- Incentiva o trabalho voluntário, como atividade não remunerada, prestada por pessoa física, cuja missão é contribuir para ajudar aos cidadãos a resolverem problemas pessoais ou sociais. ${ }^{30}$

Em relação ao mediador, como regra geral, ele é escolhido entre os membros da comunidade, porque é importante que o mesmo conheça o contexto social, os costumes, as tradições e a linguagem do local no qual o conflito se originou. Este desenvolve a atividade de forma voluntária, após ter sido capacitado para desempenhar esta função. Sua atuação deve ser pautada pela imparcialidade e equidade como condição para o êxito da mediação. ${ }^{31}$

A mediação estimula a autonomia e a responsabilidade das partes envolvidas, pois como visto anteriormente, o mediador não decide, ele estimula o diálogo entre os envolvidos para que

${ }^{29}$ CARVALHO, Aidi Lucena; BARROS NETO, Bertoldo Klinger Rego; SANTOS, Filipe Franco. A mediação comunitária como instrumento de acesso à justiça e efetivação da cidadania: uma nova perspectiva do conceito de justiça e de conflito. Disponível em: <http://www.egov.ufsc.br/portal/conteúdo>. Acesso em: 12 maio 2015.

30 PARANÁ, Ministério Público. Programa dos Núcleos de Mediação comunitária. Disponível em: <http://www.mpce.mp.br/nespeciais/nucleomed/nucleos.asp>. Acesso em:12 de maio 2015.

31 PAES DE CARVALHO, Ana Karine Pessoa Cavalcante Miranda. A mediação comunitária como instrumento de prática da cidadania e da democracia: A experiência do estado do Ceará. Disponível em: <http://www.mpce.mp.br/nespeciais/nucleomed/publicacoes/artigos/a.mediacao.comunitaria.como.inst rumento.pdf $>$. Acesso em:12 maio 2015. 
A MEDIAÇÃO COMUNITÁRIA COMO PRESSUPOSTO DE REALIZAÇÃO DO CONCEITO DE SEGURANÇA CIDADÃ: ANÁLISE DO PROGRAMA JUSTIÇA COMUNITÁRIA DESENVOLVIDO PELO TRIBUNAL DE JUSTIÇA DO DISTRITO FEDERAL

estes sejam capazes de encontrar a melhor solução para o conflito. Assim, dentre as tarefas do mediador, destaca-se:

Identificar as suas necessidades, interesses e desejos; Compreender as necessidades, interesses e desejos do outro; Identificar os pontos fundamentais do conflito; Incentivar a cooperação entre eles para resolver o problema; Explorar várias vias de solução; Analisar as possibilidades de concretizar as opções por ela pensadas. ${ }^{32}$

Quanto aos tipos de conflitos que podem ser solucionados por meio da mediação comunitária, citam-se os seguintes: conflito familiar, de vizinhança, segurança pública, reconhecimento de paternidade, conflito trabalhista, difamação, injúria, conflito na área do consumidor, societário, dissolução de união estável, ameaça, conflito escolar, entre outros. ${ }^{33}$

Destaca-se a utilidade da mediação comunitária no que tange a resolução de conflitos na área de Segurança Pública, primeiro, porque é um mecanismo célere e atua preventivamente no combate à violência, e segundo, porque a solução é encontrada pelas partes envolvidas, não há vencedores e vencidos e todos se sentem satisfeitos com o resultado obtido. ${ }^{34}$

Feitas estas considerações acerca da mediação comunitária, no próximo item será abordado o projeto Justiça Comunitária, desenvolvido pelo Tribunal de Justiça do Distrito Federal, com a finalidade de verificar os aspectos positivos de utilização dos meios alternativos de solução de conflitos.

\section{MEDIAÇÃO COMUNITÁRIA A PARTIR DO PROGRAMA DE JUSTIÇA COMUNITÁRIA DESENVOLVIDO PELO TRIBUNAL DE JUSTIÇA DO DISTRITO FEDERAL}

Importa, a priori, mencionar que a Justiça Comunitária é uma "ação que estimula a comunidade a construir e a escolher seus próprios caminhos para a realização da justiça, de

32 PARANÁ, Ministério Público. Programa dos Núcleos de Mediação comunitária. Disponível em: <http://www.mpce.mp.br/nespeciais/nucleomed/nucleos.asp>. Acesso em:12 de maio 2015..

33 Ibid.

${ }^{34}$ PAES DE CARVALHO, Ana Karine Pessoa Cavalcante Miranda. A mediação comunitária como instrumento de prática da cidadania e da democracia: A experiência do estado do Ceará. Disponível em: <http://www.mpce.mp.br/nespeciais/nucleomed/publicacoes/artigos/a.mediacao.comunitaria.como.inst rumento.pdf>. Acesso em:12 maio 2015. 
A MEDIAÇÃO COMUNITÁRIA COMO PRESSUPOSTO DE REALIZAÇÃO DO CONCEITO DE SEGURANÇA CIDADÃ: ANÁLISE DO PROGRAMA JUSTIÇA COMUNITÁRIA DESENVOLVIDO PELO TRIBUNAL DE JUSTIÇA DO DISTRITO FEDERAL

SiLVANA COLOMBO VLADIMIR PASSOS DE FREITAS

forma pacífica e solidária". ${ }^{35}$ É também uma das ações apoiadas pelo Programa Nacional de Segurança Pública com Cidadania (Pronasci) por meio de convênios com os órgãos do Poder Judiciário, como por exemplo, Defensoria Pública e Tribunais de Justiça, além do lançamento dos editais públicos para envio de propostas na referida temática.

O programa denominado Justiça Comunitária ${ }^{36}$, desenvolvido pelo Tribunal de Justiça do Distrito Federal e dos Territórios, teve seu início no ano de 2000 para atender a população do Distrito Federal com dificuldade de ter acesso à justiça. Anteriormente a este projeto, o Juizado Especial Cível TJ/DFT já realizava audiências de forma itinerante, no interior de um ônibus, nas comunidades carentes.

A ideia principal do projeto é capacitar a população para gerir seus próprios conflitos com base na participação, no diálogo e respeito aos direitos fundamentais. Para tanto, os voluntários (Agentes Comunitários de Justiça) foram capacitados para atuar como interlocutores na resolução das demandas advindas da comunidade. ${ }^{37}$ Em relação à equipe responsável pela execução do programa ${ }^{38}$, totalizam-se 53 (cinquenta e três) participantes, sendo aproximadamente 33 (trinta e três) agentes comunitários, 2 (dois) estagiários e 18 (dezoito) membros efetivos do Tribunal de Justiça do Distrito Federal e Territórios. ${ }^{39}$

Quanto à área de atuação, o programa foi instalado na Região Administrativa de Ceilândia, abrangendo uma população de 400 mil habitantes, e conta com sessenta agentes comunitários que são escolhidos por meio de processo seletivo na própria comunidade. Após a seleção inicial por uma equipe multidisciplinar os mesmos participam da capacitação permanente do Núcleo de Formação e Pesquisa em Justiça Comunitária, com a finalidade de aprender noções de Direito, técnicas de mediação comunitária, assim como participação nos debates sobre direitos humanos. Destaca-se, como primeiro ponto positivo do programa, a

\footnotetext{
${ }^{35}$ MINISTÉRIO DA JUSTIÇA. Reforma do Judiciário. Disponível em: <www.portal.mj.gov.br>. Acesso em:12 maio 2015.

${ }^{36}$ O Programa foi o vencedor da $2^{\mathrm{a}}$ edição do Prêmio Innovare em 2005, na categoria Tribunal de Justiça e tem sido apontado como referência nacional pelo Ministério da Justiça.

37 DISTRITO FEDERAL, Tribunal de Justiça. Programa Justiça comunitária. Disponível em <http://www.tjdft.jus.br/institucional/2a-vice-presidencia/nupecon/justica-comunitaria>. Acesso em:12 maio 2015.

${ }^{38}$ Os dados utilizados são do ano de 2013, pois no site do TJDFT não foi encontrado informações mais atualizadas.

39 DISTRITO FEDERAL, Tribunal de Justiça. Relatório anual do Programa Justiça Comunitária referente ao período de janeiro-dezembro/2013. Disponível em: <http://www.tjdft.jus.br/institucional/2a-vicepresidencia/nupecon/justica-comunitaria/formulariopararelatorioanualjusticacomunitaria>. Acesso em: 12 maio 2015.
} 
A MEDIAÇÃO COMUNITÁRIA COMO PRESSUPOSTO DE REALIZAÇÃO DO CONCEITO DE SEGURANÇA CIDADÃ: ANÁLISE DO PROGRAMA JUSTIÇA COMUNITÁRIA DESENVOLVIDO PELO TRIBUNAL DE JUSTIÇA DO DISTRITO FEDERAL

SiLVANA COLOMBO VLADIMIR PASSOS DE FREITAS

escolha de agentes comunitários que conheçam os valores, a linguagem e os códigos da comunidade na qual irão atuar, o que é imprescindível para o êxito da mediação comunitária.

Outro ponto a ser mencionado é o permanente cuidado com a capacitação das pessoas envolvidas no projeto. A título de informação, no ano de 2013, foram proporcionadas aos agentes comunitários 252 horas de capacitações realizadas pelo centro de formação, distribuídas entre aulas teóricas, aulas práticas, ciclo de simulação e discussões de mediação.

Os Agentes Comunitários desenvolvem as seguintes atividades: “mediação comunitária, animação de redes sociais e educação para os direitos". No ano de 2003, foram atingidas 6.628 pessoas com o referido programa e desenvolvidas 195 atividades de mediação, sendo que 60\% resultaram em acordo, além de 68 atividades de educação para os direitos. ${ }^{40}$

0 que se pretende, a partir da referidas atividades, é estabelecer um espaço de diálogo entre os integrantes da comunidade, o respeito aos direitos fundamentais e a autodeterminação. Reforça-se, com a mediação, a autonomia dos indivíduos envolvidos e a responsabilidade, já que eles serão responsáveis pela resolução dos conflitos.

Acrescenta-se, ainda, que a Coordenação do Programa Justiça Comunitária do Tribunal de Justiça do Distrito Federal e Territórios - TJDFT colaborou, no ano de 2011, com a Subsecretaria de Direitos Humanos da SEASDH do Rio de Janeiro na implantação da Justiça Comunitária no referido Estado. Esta participação se efetivou através da realização de oficinas de sensibilização sobre a referida temática desenvolvida na Cidade de Deus, Complexo do Alemão, Complexo do Borel, Morro da Providência e outras comunidades. ${ }^{41}$

A partir do exemplo apresentado, pode-se afirmar que a Justiça Comunitária encontra no uso de formas pacíficas de resolução de conflitos e na promoção dos direitos do cidadão seu principal campo de atuação. Isto vai ao encontro do paradigma da Segurança Cidadã que traz como principais pilares a mediação comunitária e a atuação preventiva dos órgãos de Segurança Pública, associada às políticas setoriais.

Dito de outra forma, a mediação comunitária é uma ferramenta essencial para a promoção da emancipação social, assim como permite o acesso à justiça, conforme determina o

\footnotetext{
${ }^{40}$ DISTRITO FEDERAL, Tribunal de Justiça. Relatório anual do Programa Justiça Comunitária referente ao período de janeiro-dezembro/2013. Disponível em: <http://www.tjdft.jus.br/institucional/2a-vicepresidencia/nupecon/justica-comunitaria/formulariopararelatorioanualjusticacomunitaria>. Acesso em: 12 maio 2015.

41 FOLEY, Gláucia Falsarella. Relatório a justiça comunitária no processo de pacificação das comunidades do Rio de Janeiro, Março a junho de 2011. Disponivel em: <http://www.tjdft.jus.br/institucional/2a-vice-presidencia/nupecon/justicacomunitaria/arquivos/RelatrioOficinasRio.pdf>. Acesso em: 12 maio2015.
} 
A MEDIAÇÃO COMUNITÁRIA COMO PRESSUPOSTO DE REALIZAÇÃO DO CONCEITO DE SEGURANÇA CIDADÃ: ANÁLISE DO PROGRAMA JUSTIÇA COMUNITÁRIA DESENVOLVIDO PELO TRIBUNAL DE JUSTIÇA DO DISTRITO FEDERAL

SILVANA COLOMBO VLADIMIR PASSOS DE FREITAS

texto constitucional, ou seja, meio para o exercício da cidadania, e não apenas uma forma de pacificação. Espera-se que as experiências positivas nessa área contribuam para a afirmação da Justiça Comunitária como política pública ${ }^{42}$ no âmbito nacional.

\section{CONCLUSÃO}

A segurança pública é um dos problemas mais latentes da sociedade atual, em razão da crescente criminalidade, o que fez surgir a necessidade de aprimoramento das práticas estatais na prestação do serviço de segurança pública na referida área, especialmente após a sua constitucionalização. 0 texto constitucional não apenas estabeleceu que a segurança pública é direito e dever dos cidadãos e do Estado, como também passou exigir que esta temática fosse pensada a partir do respeito dos direitos fundamentais, da atuação preventiva e de uma polícia mais próxima da comunidade.

Neste contexto, a prioridade do Estado brasileiro deve ser a atuação preventiva aliada à promoção da cidadania para fins de melhorar os altos índices de criminalidade e a sensação de insegurança. Esta é a ideia que permeia o paradigma de Segurança Cidadã, uma estratégia que envolve ações integrais nos ambientes onde a violência possa se fazer presente. 0 paradigma da Segurança Cidadã encontra dificuldade de implementação na ausência de articulação entre as políticas setoriais e órgãos responsáveis pela segurança, assim como na participação inexpressiva dos atores não estatais, contrariando o que determina a Constituição Federal.

Apesar disso, são notórios os esforços de todos para a implementação de práticas preventivas no combate à violência, especialmente a mediação comunitária. Um dos exemplos desta prática é o programa Justiça Comunitária desenvolvido pelo Tribunal de Justiça do Distrito Federal, que não se restringe à finalidade de pacificação, pois visa a emancipação das pessoas envolvidas.

Por fim, a mediação comunitária é um meio alternativo e eficaz de resolução de conflito porque capacita os membros da comunidade para resolverem seus próprios conflitos, incentivando-os na afirmação da autonomia e da responsabilidade dos indivíduos, sendo pilares da Segurança Cidadã.

42 “(...) Políticas Públicas são um conjunto de ações e decisões do governo, voltadas para a solução (ou não) de problemas da sociedade (...)." LOPES, Brenner; AMARAL, Jefferson Ney. Políticas Públicas: conceitos e práticas. Belo Horizonte: Sebrae/MG, 2008. 


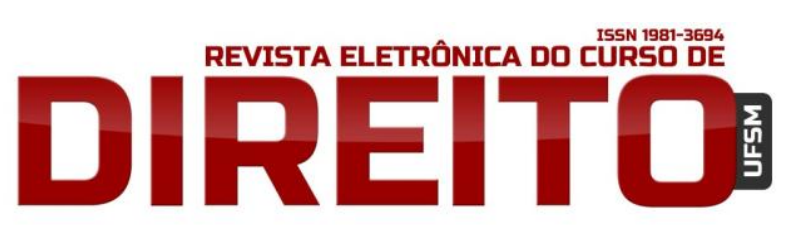

A MEDIAÇÃO COMUNITÁRIA COMO PRESSUPOSTO DE REALIZAÇÃO DO CONCEITO DE SEGURANÇA CIDADÃ: ANÁLISE DO PROGRAMA JUSTIÇA COMUNITÁRIA DESENVOLVIDO PELO TRIBUNAL DE JUSTIÇA DO DISTRITO FEDERAL

\section{REFERÊNCIAS}

ANDRADE, Vera Regina Pereira de. A Mudança do Paradigma Repressivo em Segurança Pública: reflexões criminológicas críticas em torno da proposta da $1^{\circ}$ Conferência Nacional Brasileira de Segurança Pública. Sequência, n. 67, p. 335-356, dez, 2013.

BRASIL. Supremo Tribunal Federal. Acórdão de decisão que negou provimento ao agravo regimental em recurso extraordinário sobre ingerência no poder discricionário do Poder Executivo em relação a políticas públicas. Recurso Extraordinário $n^{\circ} 559.646$. Ministério Público do Estado do Paraná e Estado do Paraná. Relator: Ministra Ellen Gracie. 07 de junho de 2011. Disponível em:

<http://redir.stf.jus.br/paginadorpub/paginador.jsp?docTP=AC\&docID=624471>. Acesso em:12 maio 2015.

CARMONA, Carlos Alberto. A Arbitragem no Processo Civil Brasileiro. São Paulo: Malheiros, 1993.

CARVALHO, Aidi Lucena; BARROS NETO, Bertoldo Klinger Rego; SANTOS, Filipe Franco. A mediação comunitária como instrumento de acesso à justiça e efetivação da cidadania: uma nova perspectiva do conceito de justiça e de conflito. Disponível em:

<http://www.egov.ufsc.br/portal/conteúdo>. Acesso em: 12 maio 2015.

CONSELHO NACIONAL DE JUSTIÇA. Resolução $\mathrm{N}^{\circ} 125$ de 29 de novembro de 2010. Disponível em: <http: //www.cnj.jus.br/atos-normativos?documento=156>. Acesso em: 12 maio 2015.

DELGADO, Maurício Goudinho. Curso de direito do trabalho. São Paulo: Ltr, 2010.

DISTRITO FEDERAL, Tribunal de Justiça. Relatório anual do Programa Justiça Comunitária referente ao período de janeiro-dezembro/2013. Disponível em:

<http://www.tjdft.jus.br/institucional/2a-vice-presidencia/nupecon/justica-

comunitaria/formulariopararelatorioanualjusticacomunitaria>. Acesso em:12 maio 2015.

DISTRITO FEDERAL, Tribunal de Justiça. Programa Justiça comunitária. Disponível em <http://www.tjdft.jus.br/institucional/2a-vice-presidencia/nupecon/justica-comunitaria>. Acesso em:12 maio 2015.

DOS SANTOS, Ricardo Stersi. Noções gerais da arbitragem. Florianópolis: Fundação Boiteux, 2004.

FIGUEIRA JÚNIOR, Joel Dias. Arbitragem. Legislação Nacional e Estrangeira e o Monopólio Jurisdicional. São Paulo: LTR, 1999.

FOLEY, Gláucia Falsarella. Relatório a justiça comunitária no processo de pacificação das comunidades do Rio de Janeiro, Março a junho de 2011. Disponivel em: 
A MEDIAÇÃO COMUNITÁRIA COMO PRESSUPOSTO DE REALIZAÇÃO DO CONCEITO DE SEGURANÇA CIDADÃ: ANÁLISE DO PROGRAMA JUSTIÇA COMUNITÁRIA DESENVOLVIDO PELO TRIBUNAL DE JUSTIÇA DO DISTRITO FEDERAL

SiLVANA COLOMBO VLADIMIR PASSOS DE FREITAS

<http://www.tjdft.jus.br/institucional/2a-vice-presidencia/nupecon/justicacomunitaria/arquivos/RelatrioOficinasRio.pdf>. Acesso em: 12 maio 2015.

FREIRE, Moema Dutra. Paradigmas de Segurança no Brasil: da Ditadura aos nossos dias. Revista Aurora, ano III, n. 5, dez, 2009.

KUHN, Thomas. S. A estrutura das revoluções científicas. São Paulo: Perspectiva, 1991. LIANA, de Paula; GODINHO, Letícia. Os governos subnacionais na gestão de segurança cidadã: experiência brasileira. Disponível em: <www.bibliotecadigital.fgv.br>. Acesso em: 12 maio 2015.

LOPES, Brenner; AMARAL, Jefferson Ney. Políticas Públicas: conceitos e práticas. Belo Horizonte: Sebrae/MG, 2008.

MARANHÃO, Ministério Público. Manual de mediação comunitária/ Adaptação de Vicente de Paulo Silva Martins. São Luís: Procuradoria Geral de Justiça, 2008.

MINISTÉRIO DA JUSTIÇA. Reforma do Judiciário. Disponível em: <www.portal.mj.gov.br>. Acesso em:12 maio 2015.

PAES DE CARVALHO, Ana Karine Pessoa Cavalcante Miranda. A mediação comunitária como instrumento de prática da cidadania e da democracia: A experiência do estado do Ceará. Disponível em:

<http://www.mpce.mp.br/nespeciais/nucleomed/publicacoes/artigos/a.mediacao.comunitaria. como.instrumento.pdf>. Acesso em:12 maio 2015.

PARANÁ, Ministério Público. Programa dos Núcleos de Mediação comunitária. Disponível em: <http://www.mpce.mp.br/nespeciais/nucleomed/nucleos.asp>. Acesso em:12 de maio 2015.

PNDU. Rumo a uma política integral de convivência de segurança cidadã na América Latina: março conceitual de interpretação-ação. Programa das Nações Unidas para o desenvolvimento, Mimeo, 2005.

SCHIAVI, Mauro. Manual de direito processual do trabalho. $3^{\circ}$ ed. São Paulo: Ltr, 2010,

SECRETARIA DE SEGURANÇA PÚBLICA DE SÃO PAULO. Polícia Comunitária. Disponível em: <WWW.ssp.sp.gov.br/acoes/acoes_comunitario.aspx>. Acesso em: 07 abr. 2015, SERRATO, Héctor Riveros. Projeto Regional de Governabilidade local para a América LatinaPNDU. Disponível em: <www.pndu.org.br/marcoconceitualpndu_segurancacidada>. Acesso em: 15 maio 2015.

SOUZA NETO, Cláudio Pereira. A segurança pública na Constituição federal de 1988: conceituação adequada, competências federativas e órgãos de execução das política. Revista de Direito do Estado, v. 8, p. 19-73, 2007.

SPENGLER, Fabiana Marion; SPENGLER NETO, Theobaldo. Mediação enquanto política pública: o conflito, a crise da jurisdição e as práticas mediativas. Santa Cruz do Sul: EDUNISC, 2012. 
ISSN 1981-3694

(DOI): $10.5902 / 1981369420057$

REVISTA ELETRÔNICA DO CURSD DE

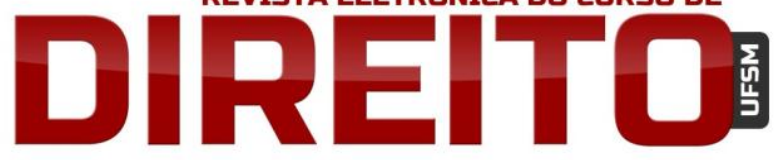

A MEDIAÇÃO COMUNITÁRIA COMO PRESSUPOSTO DE REALIZAÇÃO DO CONCEITO DE SEGURANÇA CIDADÃ: ANÁLISE DO PROGRAMA JUSTIÇA COMUNITÁRIA DESENVOLVIDO PELO TRIBUNAL DE JUSTIÇA DO DISTRITO FEDERAL

TARTUCCE, Fernanda. Mediação nos conflitos civis. Rio de Janeiro:vForense, 2008.

VEZZULLA, Juan Carlos. Teoria e Prática da Mediação. Paraná: Instituto de Mediação e Arbitragem do Brasil, 1998.

Recebido em: 17/10/2015 / Revisões requeridas em: 04/07/2016 / Aprovado em: 13/07/2016 